\title{
Delayed initiation of antenatal care and associated factors in Ethiopia: a systematic review and meta-analysis
}

\author{
Gezahegn Tesfaye ${ }^{1,2^{*}}$ (D), Deborah Loxton ${ }^{1}$, Catherine Chojenta ${ }^{1}$, Agumasie Semahegn ${ }^{2}$ and Roger Smith ${ }^{3}$
}

\begin{abstract}
Background: Antenatal care uptake is among the key indicators for monitoring the progress of maternal outcomes. Early initiation of antenatal care facilitates the timely management and treatment of pregnancy complications to reduce maternal deaths. In Ethiopia, antenatal care utilization is generally low, and delayed initiation of care is very common. We aimed to systematically identify and synthesize available evidence on delayed initiation of antenatal care and the associated factors in Ethiopia.

Methods: Studies published in English from 1 January 2002 to 30 April 2017 were systematically searched from PubMed, Medline, EMBASE, CINAHL and other relevant sources. Two authors independently reviewed the identified studies against the eligibility criteria. The included studies were critically appraised using the Joanna Briggs-MAStARI instrument for observational studies. Meta-analysis was conducted in RevMan v5.3 for Windows using a Mantel-Haenszel random effects model. The presence of statistical heterogeneity was checked using the Cochran Q test, and its level was quantified using the $\mathrm{I}^{2}$ statistics. Pooled estimate of the proportion of the outcome variable was calculated. Pooled Odd Ratios with 95\% Cl were calculated to measure the effect sizes.

Result: The pooled magnitude of delayed antenatal care in Ethiopia was $64 \%(95 \% \mathrm{Cl}: 57 \%$, 70\%). Maternal age (OR $=0$. 70; $95 \% \mathrm{Cl}: 0.53,0.93)$, place of residence $(\mathrm{OR}=0.29,95 \% \mathrm{Cl}: 0.16,0.50)$, maternal education $(\mathrm{OR}=0.49 ; 95 \% \mathrm{Cl}: 0.38,0.63)$, husband's education ( $\mathrm{OR}=0.44 ; 95 \% \mathrm{Cl}: 0.23,0.85)$, maternal occupation ( $\mathrm{OR}=0.75 ; 95 \% \mathrm{Cl}: 0.61,0.93)$, monthly income $(\mathrm{OR}=2.06 ; 95 \% \mathrm{Cl}: 1.23,3.45)$, pregnancy intention $(\mathrm{OR}=0.49 ; 95 \% \mathrm{Cl}: 0.40,0.60)$, parity $(\mathrm{OR}=0.46 ; 95 \% \mathrm{Cl}: 0.36,0.58)$, knowledge of antenatal care $(\mathrm{OR}=0.40 ; 95 \% \mathrm{Cl}: 0.32,0.51)$, women's autonomy $(\mathrm{OR}=0.38 ; 95 \% \mathrm{Cl}: 0.15,0.94)$, partner involvement ( $\mathrm{OR}=0.24 ; 95 \% \mathrm{Cl}: 0.07,0.75)$, pregnancy complications ( $\mathrm{OR}=0.23 ; 95 \% \mathrm{Cl}: 0.06,0.95)$, and means of identifying pregnancy $(\mathrm{OR}=0.50 ; 95 \% \mathrm{Cl}: 0.36,0.69)$ were significantly associated with delayed antenatal care.
\end{abstract}

Conclusion: Improving female education and women's empowerment through economic reforms, strengthening family planning programs to reduce unintended pregnancy and promoting partner involvement in pregnancy care could reduce the very high magnitude of delayed antenatal care in Ethiopia.

Trial registration: CRD42017064585.

Keywords: Delayed antenatal care, Associated factors, Ethiopia, Systematic review, Meta-analysis

\footnotetext{
*Correspondence: gezites@gmail.com; gezahegntesfaye.girma@uon.edu.au ${ }^{1}$ Research Centre for Generational Health and Ageing, Faculty of Health and Medicine, University of Newcastle, Newcastle, Australia

${ }^{2}$ School of Public Health, College of Health and Medical Sciences, Haramaya

University, Harar, Ethiopia

Full list of author information is available at the end of the article
} 


\section{Plain English summary}

A professional care provided to women during pregnancy is called antenatal care. Antenatal care plays a great role in the improvement of maternal health. In Ethiopia and other sub-Saharan African countries, antenatal care utilization among pregnant women was low. Moreover, the pregnant women in Ethiopia and other developing countries tend to postpone their first antenatal care clinic visit into the later months of pregnancy. This study summarized the existing evidence on the level of late antenatal care visit and its contributing factors among pregnant women in Ethiopia. Using different databases and other sources, this review identified twenty two relevant studies that reported late antenatal care clinic visit and its influencing factors among pregnant women in Ethiopia. We summarized and analysed the reports from the twenty two studies and put a combined assessment result on the level of late antenatal care and associated factors. Based on our review, nearly two thirds of the pregnant women in Ethiopia made their first antenatal care clinic visit late in their pregnancy. Women's non-attendance of education, husband's non-attendance of education, women's older age, rural dwelling, having previous births, unintended pregnancy, women's unemployment, low monthly income, lack of knowledge about antenatal care, lack of women's decision making power, no partner involvement, and not facing problems during pregnancy were factors associated with higher level of women's late appearance to antenatal care. Nationwide all rounded efforts targeting the major contributing factors should be established to alleviate women's late antenatal care utilization in the country.

\section{Background}

The burden of maternal mortality remains hugely varied between developing and developed countries [1]. In developing countries, the overall life time risk of woman's death due to pregnancy and related causes is estimated to be 1 in 180, while for developed countries it is about 1 in 4900 [2]. The maternal mortality ratio in Ethiopia is still high at 353 per 100,000 live births in 2015 [3], and it remains among the highest in the world. In developing countries like Ethiopia, obstetric complications during pregnancy and childbirth are the leading causes of death among reproductive aged women $[3,4]$. It is generally recognized that a lack of access to, and inadequate utilization of, antenatal care (ANC) during pregnancy contributes to adverse maternal health outcomes such as maternal mortality $[5,6]$, something which is more common in resource-poor settings. Antenatal care uptake is one of the key indicators for monitoring the progress of improving maternal outcomes. Early initiation of ANC facilitates the timely management and treatment of pregnancy complications to reduce maternal deaths [7].
In Ethiopia, the main direct causes of maternal mortality are haemorrhage, hypertensive disorders of pregnancy, unsafe abortion and puerperal sepsis $[8,9]$. These complications can be averted or otherwise treated through providing skilled care during pregnancy, child birth and in the postnatal period [2]. In 2002, the World Health Organization (WHO) recommended that pregnant women make at least four ANC visits [10]; in 2016 this recommendation was modified to at least eight visits [11], with the first ANC visit to be undertaken before the 12th week of pregnancy. While there has been marked progress in the uptake of at least one ANC attendance in Ethiopia [12-17], there has been suboptimal attendance of the recommended visits $[4,13,18,19]$. Of even more concern was the substantial proportion of women who delayed their first ANC visit to the second or third trimester of pregnancy [5, 19-21]. According to the National Demographic and Health Survey Report of Ethiopia [20], in 2014 more than three quarters of pregnant women initiated their first visit after 16 weeks of pregnancy. Early initiation of ANC plays a paramount role in enhancing maternal health as it provides an opportunity for the early screening, treatment and referral of pregnancy complications [11]. Evidence has shown that pregnant women who initiate ANC early were less likely to develop unfavourable obstetric outcomes as compared to women who entered into care after the first trimester $[22,23]$.

The key challenges that women face when seeking maternal health services were clearly explained in the three delays model [24]. This model described the barriers to utilizing maternal health services at three interrelated levels before the occurrence of maternal death. At the first level, the home or community level, women may be delayed from seeking ANC due to factors such as the low social status of women in relation to decisionmaking, poor awareness of pregnancy or birth complications, previous poor experience of care, traditional or social practices during pregnancy or childbirth, acceptance of maternal death as normal and financial dependency. In Ethiopia, there is huge gap in the level of income among women and men especially in rural parts of Ethiopia, and women are less empowered to access and control household resources [25]. This could influence their capacity to make decisions about utilization of maternal care. Moreover, the financial burden associated transportation to and from the facility and the costs incurred for the maternal care itself profoundly diminished the uptake of the care [26]. In the second level, there may be a delay in reaching a health facility which might be due to distance, unavailability of infrastructure (road or transportation) or difficult terrain. The third level of delay (delay in receiving adequate care) might be related to a shortage of, or inadequately trained health staff, and unavailability of medical supplies and equipment. 
Several studies [27-33] have investigated factors affecting delayed attendance of ANC in Ethiopia. Nonetheless, none of these studies have systematically reviewed the factors to show their overall pooled effect on delayed initiation of ANC at the national level. In addition, there were inconsistencies in attributing the influence of the factors on late initiation of ANC across various studies. For instance, there were incongruent findings on the influence of maternal education [34-37], maternal age [32-34, 36], place of residence [28, 32, 38, 39], maternal occupation $[30,34,37,40]$, marital status [32, 36, 37], husband's education [31, 32, 41], previous experience of using ANC [32, 33, 35] and history of abortion [31, 32, 42] on delayed initiation of ANC among many other factors. Hence, demonstrating a pooled effect of the factors on delayed initiation of ANC was warranted.

Previous systematic reviews conducted in developing [43, 44] and developed [45] countries have mainly reviewed evidence on the adequacy of the utilization of ANC and its related factors. In particular, the reviews covered larger geographical regions and hence failed to reflect country specific situations. Moreover, these reviews did not centre on delayed initiation of ANC as a primary outcome of interest. The objective of this review is to systematically identify and synthesize existing evidence to understand the level of delayed initiation of ANC and associated factors among reproductive aged women in Ethiopia.

\section{Method}

\section{Development of the review method}

The methodology of this systematic review was developed based on the Preferred Reporting Items for Systematic Reviews and Meta-Analyses Protocols (PRISMA-P) 2015 Statement [46] and the items in the PRISMA-P checklist were addressed (Additional file 1). The four phases that were drawn from the PRISMA flow chart ( [47]) were documented in the results to show the study selection process from initially identified records to finally included studies. The protocol for this systematic review and meta-analysis was registered in international prospective register of systematic reviews (PROSPERO) and obtained the registration number (CRD42017064585).

\section{Search strategy}

The literature search was carried out by the primary author (GT). The search was limited to papers published in English from 1 January 2002 to 30 April 2017. The year 2002 was selected, since WHO had introduced the Focused ANC model [10] by this year. We applied $\mathrm{MeSH}$ terms, Emtree, CINAHL headings and combined key words to identify studies in the databases. Major medical electronic databases such as PubMed, Medline
(OVID interface), Excerpta Medica (Embase) (OVID interface), and CINAHL (EBSCO host) were used to identify relevant literature for the review. To cover grey literature, we hand-searched literature using the Google search engine and Google Scholar; official WHO websites; online libraries of academic and government institutions and references of electronically identified articles. The search strings or terms were stemmed from the following key words: delayed initiation, ANC, associated factors, and Ethiopia. The search terms were used to retrieve relevant literature in combined form adapted to the requirement of the specific database. Further information regarding the search strategy of the selected databases is attached (Additional file 2).

\section{Eligibility criteria}

We included all observational studies as well as Demographic and Health Surveys (DHS) reports. We considered studies that examined the level and factors associated with delayed initiation of ANC among reproductive aged women (15-49 years) who were pregnant or gave birth at least once and who live in Ethiopia. We included studies that defined the main outcome variable "delayed initiation of ANC" as entry into care after at least 12 weeks of pregnancy, including studies that defined delayed initiation of ANC as entry into the care after 16 weeks of gestation. Studies that had been conducted in either a community or facility setting and which involved analysis of primary or secondary data were included. We included studies that had measure of association statistics or had test statistic that explicitly demonstrated the influence of the predictors on delayed initiation of ANC or had a crosstab showing the difference in magnitude of the outcome variable in the categories of the predicting variables. We excluded reviews, editorials, case series and case reports on delayed initiation of ANC. We also excluded studies that only reported qualitative findings on delayed ANC initiation. In studies that reported both quantitative and qualitative results, we only considered the quantitative findings.

\section{Study selection procedure \\ Screening}

First studies were identified through applying the search strings and the filters in the databases as well as other relevant sources. The identified studies were exported to the citation manager (EndNote) [48] and duplicates were excluded. The two authors (GT and AS) independently screened the studies based on the information contained in the titles and abstracts according to the inclusion criteria. Based on this screening, the titles and abstracts of the studies were classified as included, excluded, and undecided. We then obtained the full texts of all the included and the undecided studies for further eligibility assessment. 


\section{Eligibility of studies}

The two authors (GT and AS) independently reviewed the full texts of the included and undecided categories of the studies against the eligibility criteria for final inclusion. Studies that were not eligible based on the examination of the full-text were excluded and the reasons for the exclusion were described. Disagreements between the two reviewers were resolved through discussion and consensus.

\section{Quality assessment}

All of the included studies were critically appraised for their validity. The two authors (GT and AS) checked the methodological robustness and validity of the findings using the JBI (Joanna Briggs Institute) Meta-Analysis of Statistics Assessment and Review Instrument (MAStARI) [49]. Particular attention was given to a clear statement of the objective of the study, inclusion criteria, randomness of subject selection, identification of the study subjects, and preciseness of measurement of outcomes of interest and use of appropriate statistical analysis method, as well as documentation of sources of bias or confounding. Uncertainties were resolved by joint discussion between the reviewers. The level of agreement between the two reviewers was judged using the Cohen's Kappa (K) coefficient statistics. To calculate " $K$ " a two by two contingency table was constructed with "High" and "Low" categories of quality assessment provided independently by the two reviewers based on set of criteria. We obtained " $K$ " value of $(0.80)$, and thus the level of agreement was satisfactory. In order to minimize publication bias, we searched and included both published and unpublished literature. We obtained unpublished literatures (grey literatures) through hand-searching of online libraries of academic institutions, government organizations, and agencies in addition to using Google search engine and Google scholar. We also contacted an author to seek data that was not clearly reported in the article.

\section{Data extraction process}

A structured data extraction template in the form of summary table was constructed for the data abstraction. The two authors (GT and AS) systematically used the data extraction template to abstract data. The summary table contained list of items pertaining to the study characteristics to concisely present all the included studies. The specific list of items included; study year, design of the study, study setting, sample size, study subjects, data collection method, and study specific predicting factors. A quantitative data of cross-tabulation between the subject's characteristics (predicting factors) and the outcome variable was also systematically abstracted. During the data extraction of the exposure variables, we categorized the individual classifications shown for each variable in the studies into two (exposed with the outcome and non-exposed with the outcome). The non-exposed category was considered as the reference category of the variables (e.g for place of residence, urban was the exposed and rural was the non-exposed category). We then put the corresponding combined numerical value to make it ready for the quantitative synthesis. During the data extraction, one of the papers (Bayou et al. 2016) reported missing and incomplete data, and the principal author of the publication was contacted to request further data via email. We received a response from the author, and were provided with the requested data. Disagreements between the two review authors were resolved by face to face discussion and reached a consensus.

\section{Data synthesis and statistical analysis}

The individual studies were concisely described using a summary table. The summary table particularly described the characteristics of the included studies and the main findings. We conducted the quantitative synthesis using the Cochrane community Review Manager Software (RevMan version 5.3 for windows) [50]. Summary statistics (pooled effect sizes) in Odds Ratios with 95\% confidence intervals were calculated. We classified the factors that showed significant association with the outcome variable into three groups based on the three delays model, though some overlapping exist between them. Forest plots were used to graphically present the meta-analysis results. The presence of statistical heterogeneity was checked by using the $\mathrm{Chi}^{2}$ test (Cochran Q test) at $p$-value $\leq 0.05$. The level of heterogeneity among the studies was quantified using the $\mathrm{I}^{2}$ statistics [51] where substantial heterogeneity was assumed if the $\mathrm{I}^{2}$ value was $\geq 50 \%$. We conducted meta-analysis using Mantel-Haenszel random effects model when the studies were substantially heterogeneous ( $\mathrm{I}^{2}$ statistic $\geq 50 \%$ ). Pooled estimate of the magnitude of the primary outcome variable was conducted using stats direct (http://www.statsdirect. com) statistical software [52] using Stuart-Ord (inverse double arcsine square root) method. We hypothesized that there could be variation in the factors that lead to delayed ANC between studies that defined delayed ANC based on the WHO [10] recommendation with $(\geq 12$ weeks) and country specific recommendation [53] ( $\geq 16$ weeks) due to the obvious difference in magnitude of the outcome variable. Hence, subgroup analysis was conducted based on comparison of outcomes for studies that defined delayed initiation of ANC based on ( $\geq 12$ weeks) and ( $\geq 16$ weeks), provided an adequate number of studies were available in the two groups. The result of the review was reported according to the PRISMA guideline for reporting [54]. 


\section{Results}

\section{Description of the studies}

We retrieved 2975 studies through searching the major health and medical electronic databases and other relevant sources. From all the identified studies, 1006 articles were removed due to duplication while 1969 studies were retained for further screening. The remaining 1969 studies were then screened for their eligibility based on the title and abstract. Accordingly, 1867 studies were excluded because of the incompatibility of the content presented in the title and abstract of the studies with our review topic. Hence, the full text of the remaining 102 studies were assessed for eligibility. During the full text assessment, 80 studies were excluded from the review because of duplication, inconsistent study outcome, or irrelevant target participants. The remaining twenty two studies were critically appraised and included in the review. After the critical appraisal of the studies, we excluded one study from the quantitative synthesis due to the relatively poor methodological quality and inconsistent statistical report. Finally, twenty one studies were included for the pooled estimation of delayed initiation of ANC and factor analysis (Fig. 1). Among the included studies, there were seventeen published articles, three master theses, and one Ethiopian Demographic and Health Survey (DHS data). All of the included studies were crosssectional by design and seventeen of the studies were conducted in a facility setting (Table 1 ). Ten of the studies included in the quantitative synthesis reported delayed initiation of ANC based on ( $\geq 12$ weeks), and the remaining studies reported it based on ( $\geq 16$ weeks).

With regards to the demographic characteristics, the study participants in the included studies were pregnant women or women who have at least had one birth in the five or three years prior to the studies. The age of the participants' were ranged from 15 to 49 years. Large majority of the participants in the included studies were urban residents. Moreover, higher proportion of the participants in the included studies were married and attended formal education (primary school and above).

\section{Magnitude of delayed initiation of ANC}

The pooled estimate of the magnitude of delayed initiation of ANC in Ethiopia was 64\% (95\% CI: 57\%, 70\%) (Fig. 2). The result of the analysis for the magnitude of delayed initiation of ANC based on the studies that reported the outcome variable with ( $\geq 12$ weeks) was $66 \%$ (95\% CI: 56\%, 76\%), whereas based on the studies that defined the outcome variable with ( $\geq 16$ weeks) it was 62\% (95\% CI: 52\%, 71\%).

\section{Factors associated with delayed initiation of ANC}

The current review revealed various factors associated with delayed initiation of ANC in Ethiopia. Significantly associated delay one factors include maternal age, maternal education, husband's education, pregnancy intention, women's autonomy, knowledge on ANC, partner involvement, pregnancy complication, and parity. Significantly associated delay two factors were maternal occupation, monthly income and place of residence. Means of checking pregnancy was the only delay three factor that showed statistically significant association with delayed ANC. The review also demonstrated that delay one factors such marital status and history of abortion, and delay three factor (previous use of $\mathrm{ANC}$ ) were not significant predictors of delayed attendance of ANC services (Table 2).

\section{Maternal age}

Maternal age was significantly associated with delayed initiation of ANC. Women aged between 15 and 30 were less likely to have delayed their first ANC booking as compared to women aged 31 to 49 years of age (OR, 0.70; 95\% CI: 0.53, 0.93). However, the subgroup (delayed initiation $\geq 16$ weeks) showed no association between maternal age and delayed booking of ANC (OR, 0.70; 95\% CI: $0.42,1.19)$. But it did not affect the overall association. Random effect model was employed for the analysis as the $\mathrm{I}^{2}$ value was $>50 \%$ (Fig. 3 ).

\section{Maternal education}

The meta-analysis showed that maternal education was significantly associated with delayed ANC initiation. The overall Odds Ratio 0.49 at 95\% CI: $0.38,0.63$ indicated that women who have attended primary or above level of education were less likely to delay their first ANC visit as compared to women without formal education. In spite of the heterogeneity of the studies, the finding showed statistically significant association. The subgroup analysis for studies with ( $\geq 12$ weeks) (OR, 0.57; 95\% CI: $0.45,0.72)$ and studies ( $\geq 16$ weeks) (OR, 0.43 ; 95\% CI: $0.28,0.67)$ both showed significant association between the maternal educational status and delayed initiation of ANC. We used random effect model for the analysis since the $\mathrm{I}^{2}$ value was $75 \%$ (Fig. 4).

\section{Place of residence}

According to the factor analysis of the included studies, place of residence was significantly associated with delayed initiation of ANC. Women who live in urban area were less likely to have delayed initiation of ANC (OR, 0.29 , 95\% CI: 0.16, 0.50). No difference was found in terms of the direction of association between place of residence and delayed initiation of ANC in the subgroups analysis. Random effect model was used for the analysis since the heterogeneity test showed an overall $\mathrm{I}^{2}$ value of $89 \%$ (Fig. 5). 


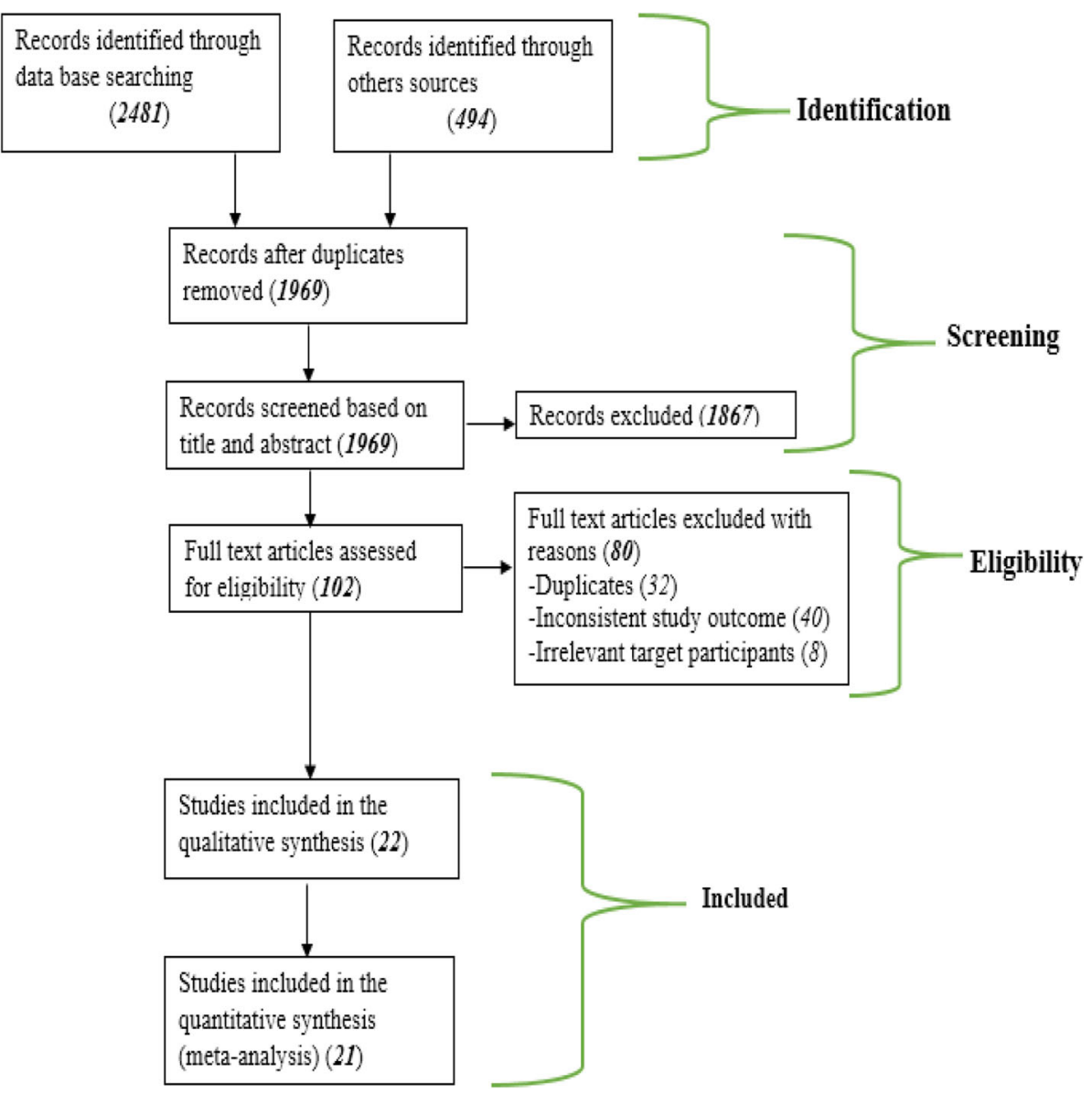

Fig. 1 Schematic presentation of the PRISMA flow diagram to select and include studies

\section{Pregnancy intention}

The review finding showed that women with intended pregnancy were less likely to delay their ANC initiation (OR, 0.49; 95\% CI: 0.40, 0.60). There was no difference between the subgroups in the direction of association. As the heterogeneity test indicated an $\mathrm{I}^{2}$ value of $59 \%$, random effect was considered for the analysis (Fig. 6).

Below are the descriptions of other factors that are associated with delayed initiation of ANC with the metaanalysis test statistics (Table 3 ).

\section{Family monthly income}

Monthly average family income was significantly associated with delayed ANC initiation. It was demonstrated that there was increased odds of delayed initiation of ANC among women with an average family income of $\leq 1000$ ETB (50USD) compared to those women whose average family income was $>1000$ ETB (50USD) (OR, 2.06; 95\% CI: 1.23, 3.45). The association between family monthly income and delayed initiation of antennal care was not consistent across the two subgroups, where the subgroup which defined the outcome variable based on
( $\geq 16$ weeks) showed insignificant association between monthly income and delayed initiation of ANC (OR, 2.26; 95\% CI: 0.96, 5.29), whereas the subgroup (delayed ANC $\geq 12$ weeks) (OR, 1.77; 95\% CI: 1.16, 2.72) showed significant association. Due to the heterogeneity of the studies $\left(\mathrm{I}^{2}=91 \%\right)$, we used random effect model for the analysis.

\section{Marital status}

Our systematic review demonstrated that there was no significant association between marital status and delayed initiation of ANC (OR, 0.81; 95\% CI: 0.56, 1.16). The same was true in the subgroup analysis which showed no association between marital status and delayed initiation of ANC. We assumed random effect model for the analysis since the $\mathrm{I}^{2}$ statistics showed presence of heterogeneity (68\%).

\section{Maternal occupation}

The overall Odds Ratio showed that there was significant association between maternal occupation and delayed initiation of ANC (OR, 0.75; 95\% CI: 0.61, 0.93). 


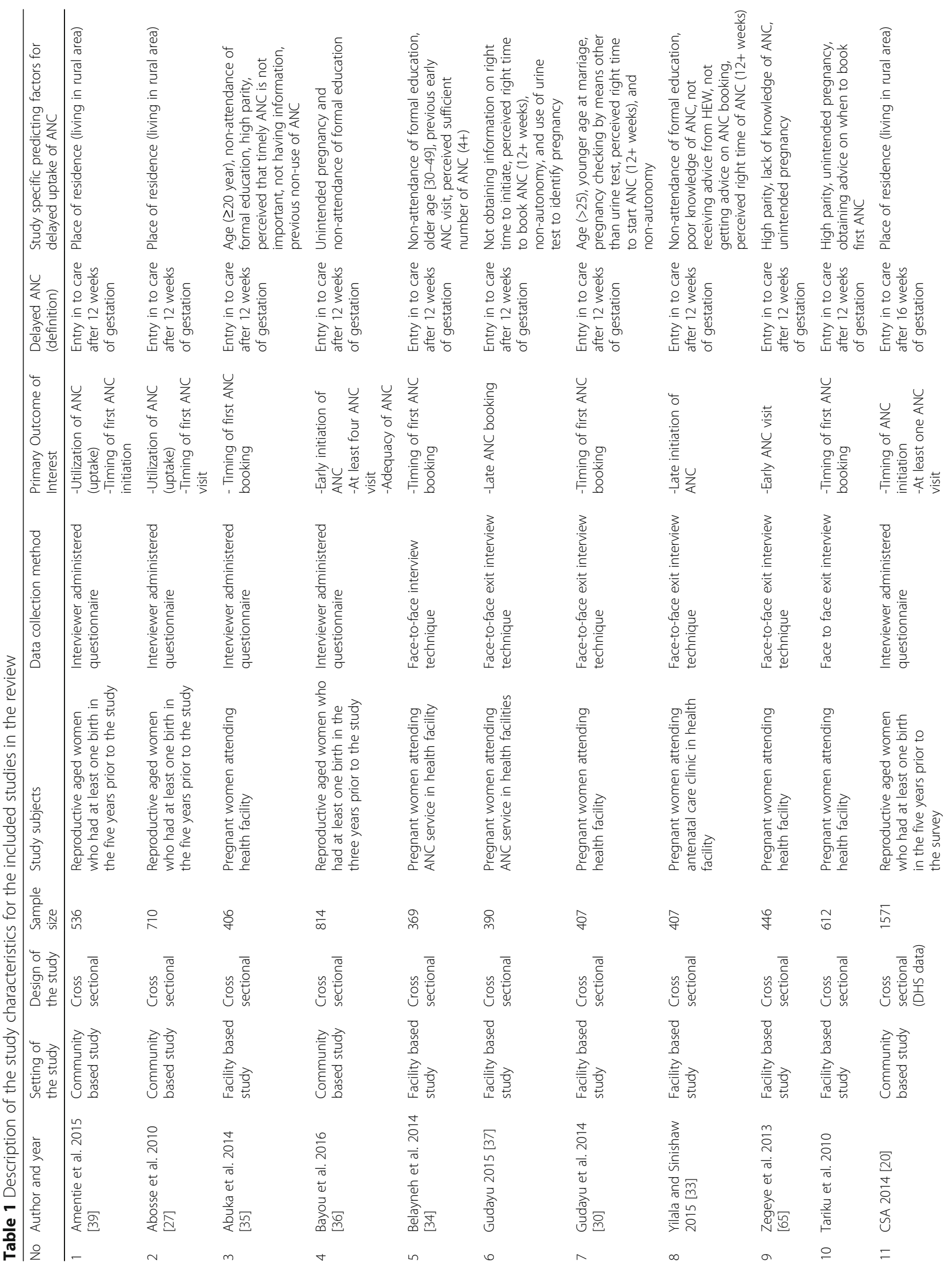




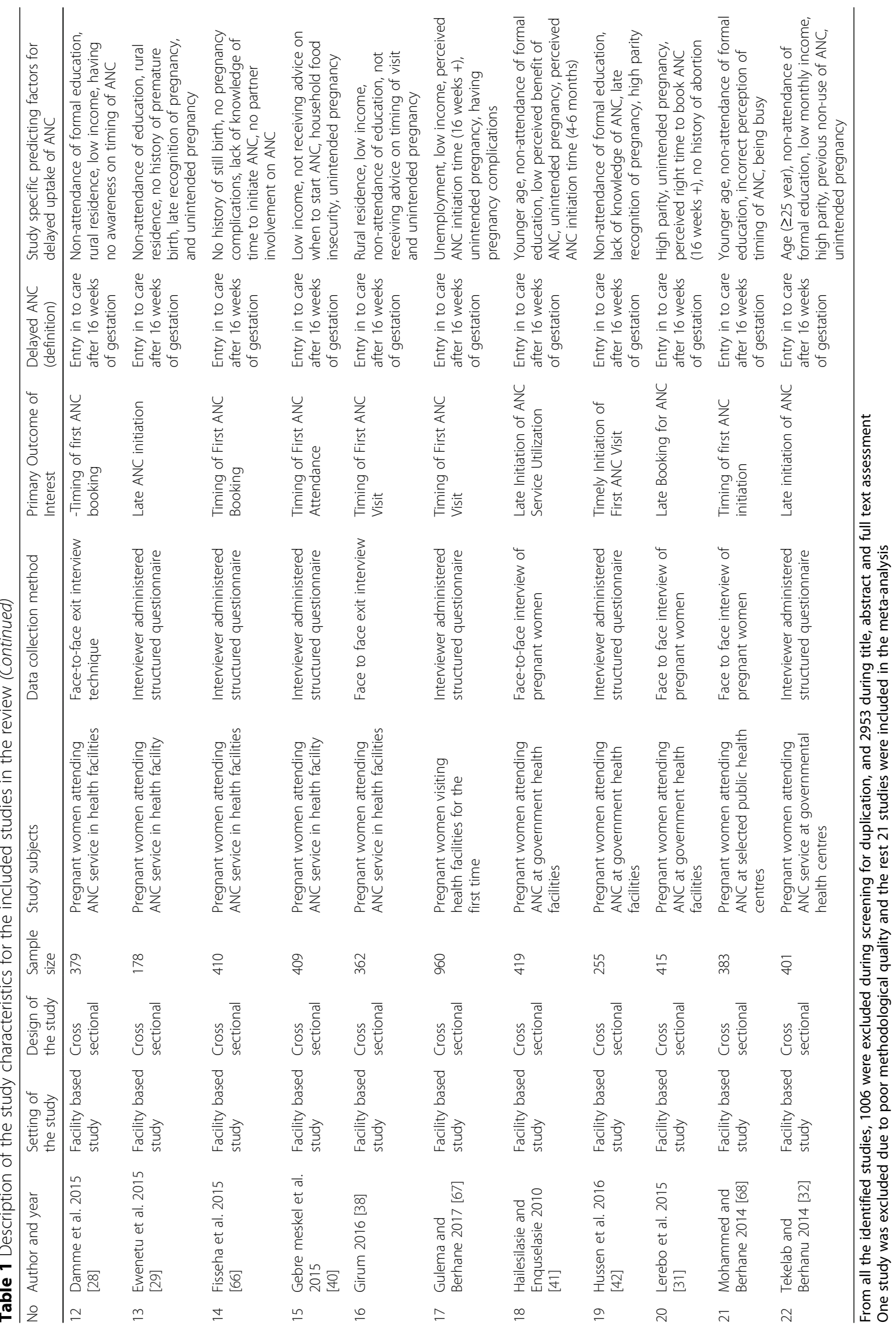


Proportion meta-analysis plot [random effects]

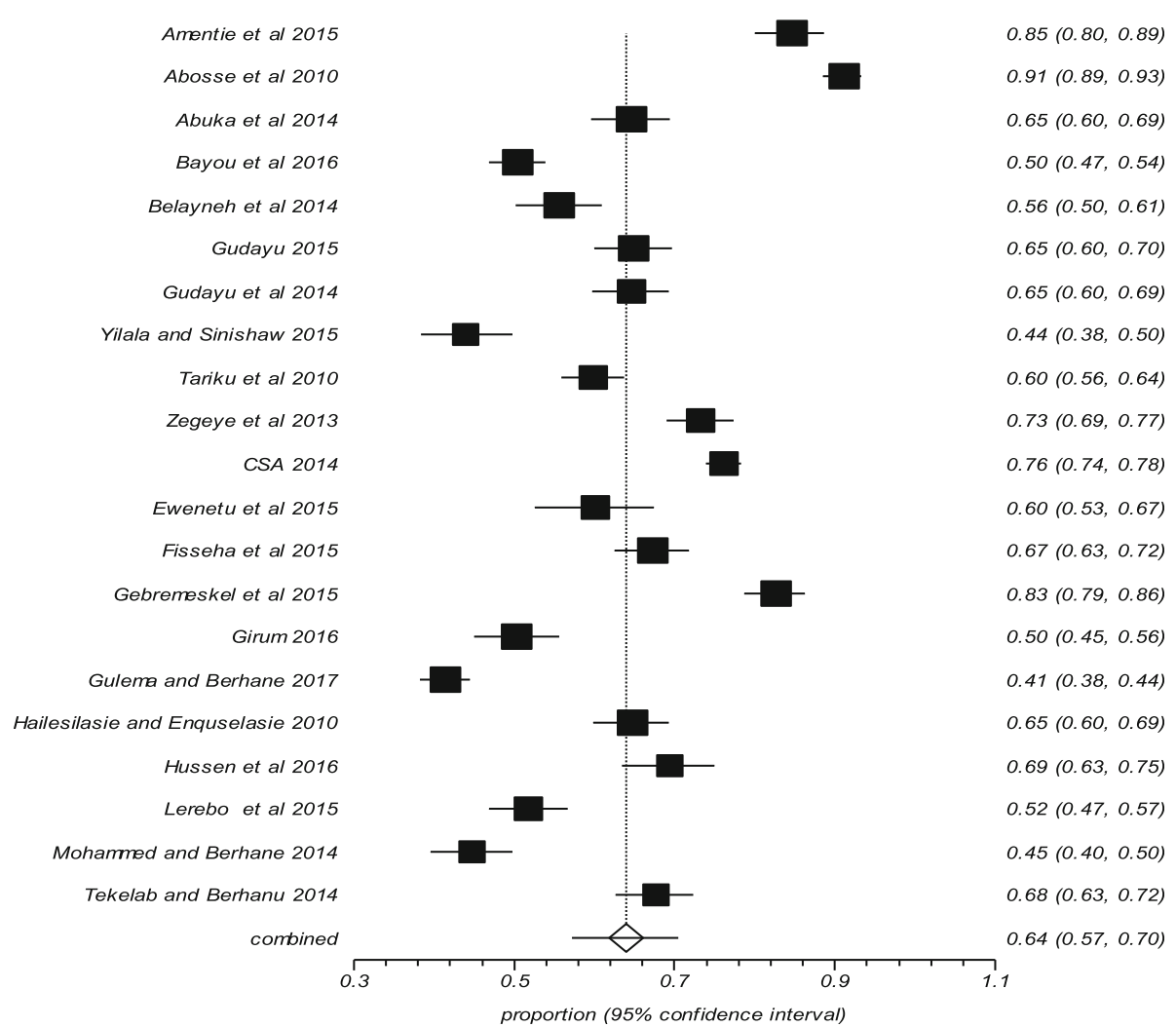

Fig. 2 Pooled estimation of delayed initiation of ANC in Ethiopia, 2002-2017. NB ( $)$ : Overall combined pooled proportion, and $\mathbf{m}$ : Original studies proportion)

Employed women were less likely to delay their ANC as compared to their counterparts. However, the subgroup (delayed ANC initiation $\geq 12$ weeks) (OR, 0.76; 95\% CI: $0.53,1.09)$ showed no association between maternal occupation and delayed booking of ANC. But the overall association was not altered. The heterogeneity test showed an $\mathrm{I}^{2}$ value of $74 \%$, and therefore random effect model was considered for the analysis.

\section{Husband's education}

Association between husband's education and delayed initiation of ANC was carried out in one group of studies that

Table 2 Overview of factors associated with delayed initiation of ANC according to the three delay model in Ethiopia, 2002-2017

\begin{tabular}{|c|c|c|}
\hline \multirow{2}{*}{$\begin{array}{l}\text { Category of the } \\
\text { factors }\end{array}$} & \multicolumn{2}{|c|}{ Significantly associated with delayed ANC (COR at 95\% Cl) } \\
\hline & Yes & No \\
\hline Delay one & $\begin{array}{l}\text { Maternal age } \\
\text { Maternal education } \\
\text { Husband's education } \\
\text { Pregnancy intention } \\
\text { Women's autonomy } \\
\text { Partner involvement } \\
\text { Knowledge on ANC } \\
\text { Presence of pregnancy complication } \\
\text { Parity }\end{array}$ & $\begin{array}{l}\text { History of abortion } \\
\text { Marital status }\end{array}$ \\
\hline Delay two & $\begin{array}{l}\text { Place of residence } \\
\text { Maternal occupation } \\
\text { Monthly income }\end{array}$ & \\
\hline Delay three & Means of checking pregnancy & Previous ANC utilization \\
\hline
\end{tabular}




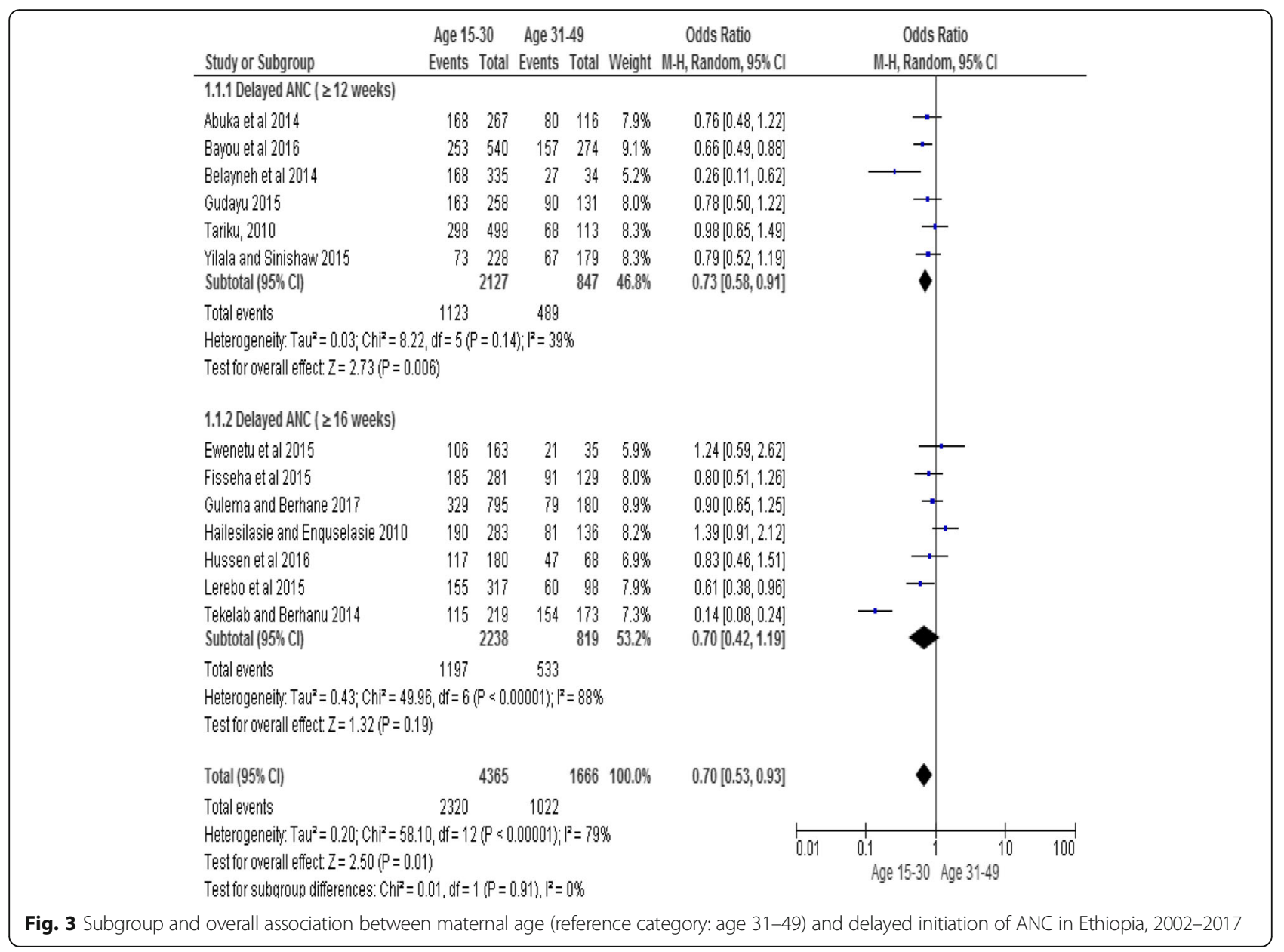

defined the outcome variable with ( $\geq 16$ weeks), as this variable was not reported in the other group of studies. The analysis showed that women having a husband who attended formal education were less likely to delay their first antenatal visit as compared to those women whose husband had never attended formal education (OR, 0.44; 95\% CI: 0.23, 0.85). Random effect model was implemented for the analysis since the $\mathrm{I}^{2}$ value was greater than $50 \%$.

\section{Women's autonomy}

We conducted analysis of a single group of studies that defined the outcome variable with ( $\geq 12$ weeks) due to the unavailability of corresponding data about women's autonomy in the other group of studies. Accordingly, the analysis result revealed that women's autonomy has a significant association with delayed initiation of ANC (OR, 0.38; 95\% CI: 0.15, 0.94). Autonomous women were less likely to initiate their first ANC later than non-autonomous women. Random effect model was used for the analysis as the $\mathrm{I}^{2}$ test result is $89 \%$.

\section{Previous use of ANC}

The finding revealed that there was no significant association between previous utilization of ANC and delayed initiation of ANC (OR, 0.62; 95\% CI: 0.34, 1.11). This was the case in both subgroups of the studies, and the overall analysis result. We assumed a random effect model for the analysis as the $\mathrm{I}^{2}$ value $85 \%$ showed substantial heterogeneity between the studies.

\section{Parity}

Parity was another predicting factor that affected delayed initiation of ANC. In this regard, women with no parity (nulliparous) were less likely to have delayed their ANC initiation as compared to women who were primipara and above. This was demonstrated in the overall Odds Ratio, 0.46 at $95 \%$ CI: $0.36,0.58$. There was no difference in the association between parity and delayed initiation of ANC in the subgroup analysis. Since the $\mathrm{I}^{2}$ value was $67 \%$, indicating considerable heterogeneity of the included studies, we assumed a random effect model for the analysis. 


\begin{tabular}{|c|c|c|c|c|c|c|c|}
\hline & Study or Subgroup & $\begin{array}{l}\text { Attended } \\
\text { Events Total }\end{array}$ & $\begin{array}{l}\text { Never atte } \\
\text { Events }\end{array}$ & $\begin{array}{l}\text { anded } \\
\text { Total Weight }\end{array}$ & $\begin{array}{l}\text { Odds Ratio } \\
\text { M.H,Random, } 954 \mathrm{Cl}\end{array}$ & $\begin{array}{r}\text { Odds R } \\
\text { M-H, Randon }\end{array}$ & $\begin{array}{l}\text { Patio } \\
\text { om, }, 95 \%, \mathrm{Cl}\end{array}$ \\
\hline & 1.1.1.1 Delayed AlC ( 212 weeks) & & & & & & \\
\hline & Abukk et a a 2014 & $194 \quad 322$ & 56 & $65 \quad 4.7 \%$ & $0.24[0.12,0.51]$ & - & \\
\hline & Bayou et al 2016 & 345711 & 65 & $1036.3 \%$ & $0.55[0.36,0.84]$ & $\longrightarrow$ & \\
\hline & Belayneh et al 2014 & 156279 & 39 & $72 \quad 5.8 \%$ & $1.07[0.64,1.81]$ & $\longrightarrow$ & 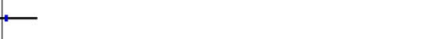 \\
\hline & Guday 2015 & 117202 & 136 & $180 \quad 6.3 \%$ & $0.53[0.34,0.80]$ & $\rightarrow$ & \\
\hline & Guday et al 2014 & $124 \quad 215$ & 139 & $1926.4 \%$ & $0.52[0.34,0.79]$ & $\rightarrow$ & \\
\hline & Tariku et al 2015 & $278 \quad 477$ & 88 & $135 \quad 6.5 \%$ & $0.75[0.50,1.11]$ & $\rightarrow$ & \\
\hline & Yllala and Sinishaw 2015 & 93309 & 47 & $98 \quad 6.1 \%$ & $0.47[0.29,0.74]$ & $\longrightarrow$ & \\
\hline & Zegeje etal 2013 & $257 \quad 357$ & 72 & $895.5 \%$ & $0.61[0.34,1.08]$ & 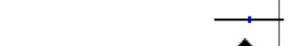 & \\
\hline & Subtotal $\mid 955 \mathrm{C}(\mathrm{C})$ & 2872 & & $942 \quad 47.6 \%$ & $0.57[0.45,0.72]$ & 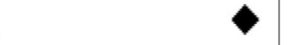 & \\
\hline & Total events & 1564 & 642 & & & & \\
\hline & Heterogonenity: $\operatorname{Tal}^{2}=0.066^{\circ} \mathrm{Ch}^{2}=13.8$ & $61, d f=?(P=0.0$ & $006)_{1}^{2}=490$ & & & & \\
\hline & Tessfor overala lefect $z=4.65(P<0.0$ & & & & & & \\
\hline & 1.1.2 Delayed Alic (z 16 weeks) & & & & & & \\
\hline & Ewenentu ef a 2015 & $27 \quad 55$ & 80 & $1235.1 \%$ & $0.52[0.27,0.99]$ & & \\
\hline & Fissehta etal 2015 & 220336 & 56 & $74 \quad 5.5 \%$ & $0.61[0.34,1.09]$ & & \\
\hline & Gebremeskele etal 2015 & 230292 & 108 & $117 \quad 4.7 \%$ & $0.31[0.15,0.05]$ & & \\
\hline & Givum 2016 & 131289 & 51 & $735.6 \%$ & $0.36[0.21,0.62]$ & & \\
\hline & Gulema and Behane 2017 & 350878 & 60 & $114 \quad 6.5 \%$ & $0.60[0.40,0.88]$ & & \\
\hline & Hailessilasie and Enquselasie 2010 & 193329 & 78 & $90 \quad 5.1 \%$ & $0.22[0.11,0.42]$ & 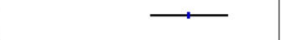 & \\
\hline & Hussen etalal 2016 & 161239 & 9 & $163.4 \%$ & $1.61[0.58,4.47]$ & & \\
\hline & Lerebo et ala 2015 & 192375 & 23 & $405.1 \%$ & $0.78[0.40,1.50]$ & & - \\
\hline & Mohammed and Berhane 2014 & $137 \quad 323$ & 34 & $605.6 \%$ & $0.56[0.32,0.98]$ & 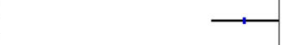 & \\
\hline & Tekelab and Berhanu 2014 & 85185 & 184 & $207 \quad 5.8 \%$ & $0.11[0.06,0.18]$ & $\longrightarrow$ & \\
\hline & Subtotal (95Y Cl) & 3301 & & $91452.4 \%$ & $0.43[0.28,0.67]$ & & \\
\hline & Total events & 1726 & 683 & & & & \\
\hline & Heterogeneneity: Tau ${ }^{2}=0.39 ;$ Chi $^{2}=47.9$ & $94, c f=9(p<0,0$. & $00001)_{1}^{\prime}=$ & & & & \\
\hline & Tess for overal effect $Z=3.76(P=0.0$ & & & & & & \\
\hline & Total $\mid 95 \mathrm{C}(\mathrm{Cl})$ & 6173 & & $1856100.0 \%$ & $0.49[0.38,0.63]$ & & \\
\hline & Total everents & 3200 & 1325 & & & & \\
\hline & Heterogenenity: Tau ${ }^{2}=0.22 ;$ Chi $^{2}=68.2$ & $29,6 f=17 \mathbb{P}<0$. & $0.00001) ; 1^{2}=$ & & & \begin{tabular}{|l|l}
0.01 & 1
\end{tabular} & 10 \\
\hline & Testfor overal effect $z=5.56$ ( $<<0.0$ & & & & & Attended forma leducation (primary and above) I & Never attended formal educcation \\
\hline & Test for suboroun differences: $\mathrm{Ch}^{2}=1$ & $1.18, d f=1 / P=0$ & $0.28)^{2}=15$ & & & & \\
\hline $\begin{array}{l}\text { Fig. } 4 \text { Subgroup a } \\
\text { initiation of ANC in }\end{array}$ & $\begin{array}{l}\text { d overall association } \\
\text { Ethiopia, 2002-2017 }\end{array}$ & between & n mate & ernal edu & cation (refere & ence category: never atter & ended formal education) and delayed \\
\hline
\end{tabular}

\section{Partner involvement}

We conducted the analysis using studies from both subgroups and it was found that partner involvement has a significant association with delayed initiation of ANC. Women who had a partner who was involved in ANC were less likely to delay thier first ANC initiation compared with women with no partner involvement in ANC (OR, 0.24; 95\% CI: 0.07, 0.75). We considered a random effect model for the analysis because the $\mathrm{I}^{2}$ value was $85 \%$.

\section{Knowledge of ANC}

The overall analysis of both groups of studies showed that knowledge of ANC has association with delayed initiation of ANC. Knowledgeable women were less likely to delay their ANC booking as compared to nonknowledgeable women (OR, 0.40; 95\% CI: 0.32, 0.51). Fixed effect model was assumed for the analysis as the Chi square test (7.08) with the $p$-value (0.21) showed statistically insignificant heterogeneity among the included studies for this factor analysis.

\section{History of abortion}

We found no significant association between history of abortion and delayed initiation of ANC (OR, 1.16; 95\% CI: $0.79,1.69)$, and this was true in the analysis result of both subgroups of studies. We assumed a random effect model since the $\mathrm{I}^{2}$ statistics $(77 \%)$ showed substantial heterogeneity.

\section{Pregnancy complications}

There was significant association between the presence of complications during pregnancy and delayed initiation of ANC on a single group analysis (delayed initiation of $\mathrm{ANC} \geq 16$ weeks). Women who experienced complications during pregnancy were less likely to delay their first ANC attendance compared to women who did not 


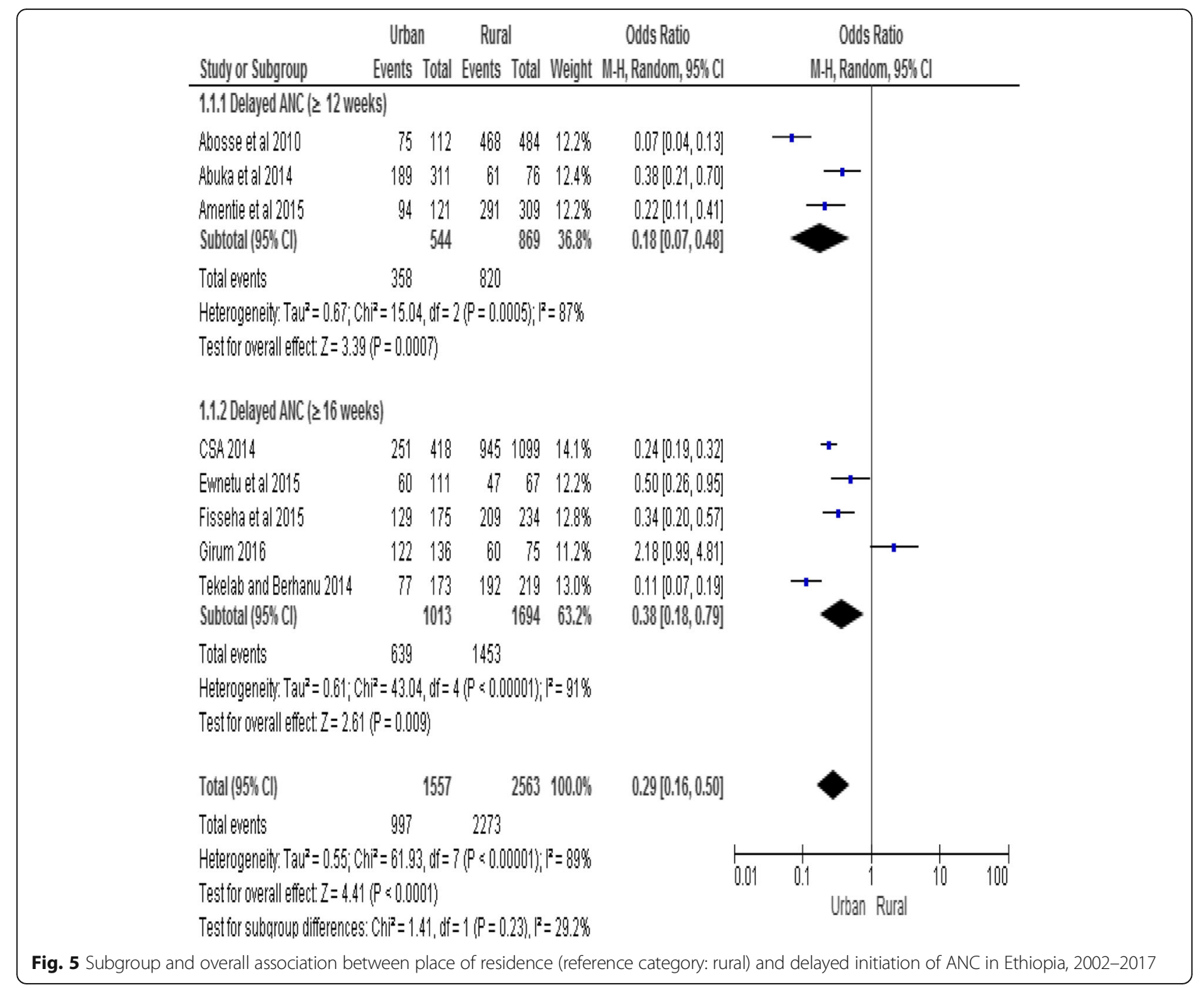

experience complications during pregnancy (OR, 0.23; 95\% CI: 0.06, 0.95). Random effect model was used for the analysis since the $\mathrm{I}^{2}$ value was greater than $50 \%$.

\section{Means of identifying pregnancy}

No sub-group analysis was performed due to lack of relevant statistics with regards to means of identifying pregnancy in one group (delayed initiation of ANC $\geq 16$ weeks). Single group (delayed initiation of ANC $\geq 12$ weeks) analysis however showed a significant association between means of identifying pregnancy with delayed initiation of ANC. Women who identified their pregnancy with a urine test were less likely to delay their first ANC visit as compared to women who identified their pregnancy using other means (OR, 0.50; 95\% CI: 0.36, 0.69). We considered random effect model for the analysis since the $\mathrm{I}^{2}$ value was greater than $50 \%$.

\section{Discussion}

Maternal age, maternal education, husband's education, maternal occupation, place of residence, parity, knowledge of ANC, women's autonomy, partner involvement, pregnancy intention, presence of pregnancy complications, and means of identifying pregnancy were significantly associated factors for delayed initiation of ANC in Ethiopia. We found out that nearly two thirds of the women in Ethiopia initiated their first ANC late after $12^{\text {th }}$ week of pregnancy. Marital status, history of abortion and previous use of ANC showed no significant association with delayed initiation of ANC.

Timely initiation and continuous attendance of ANC is believed to improve maternal health outcomes [23, 55]. This is the case particularly in developing countries where the health status of women is very poor. It is imperative to understand the overall level of delayed initiation of ANC and the contributing factors at the country level to inform 


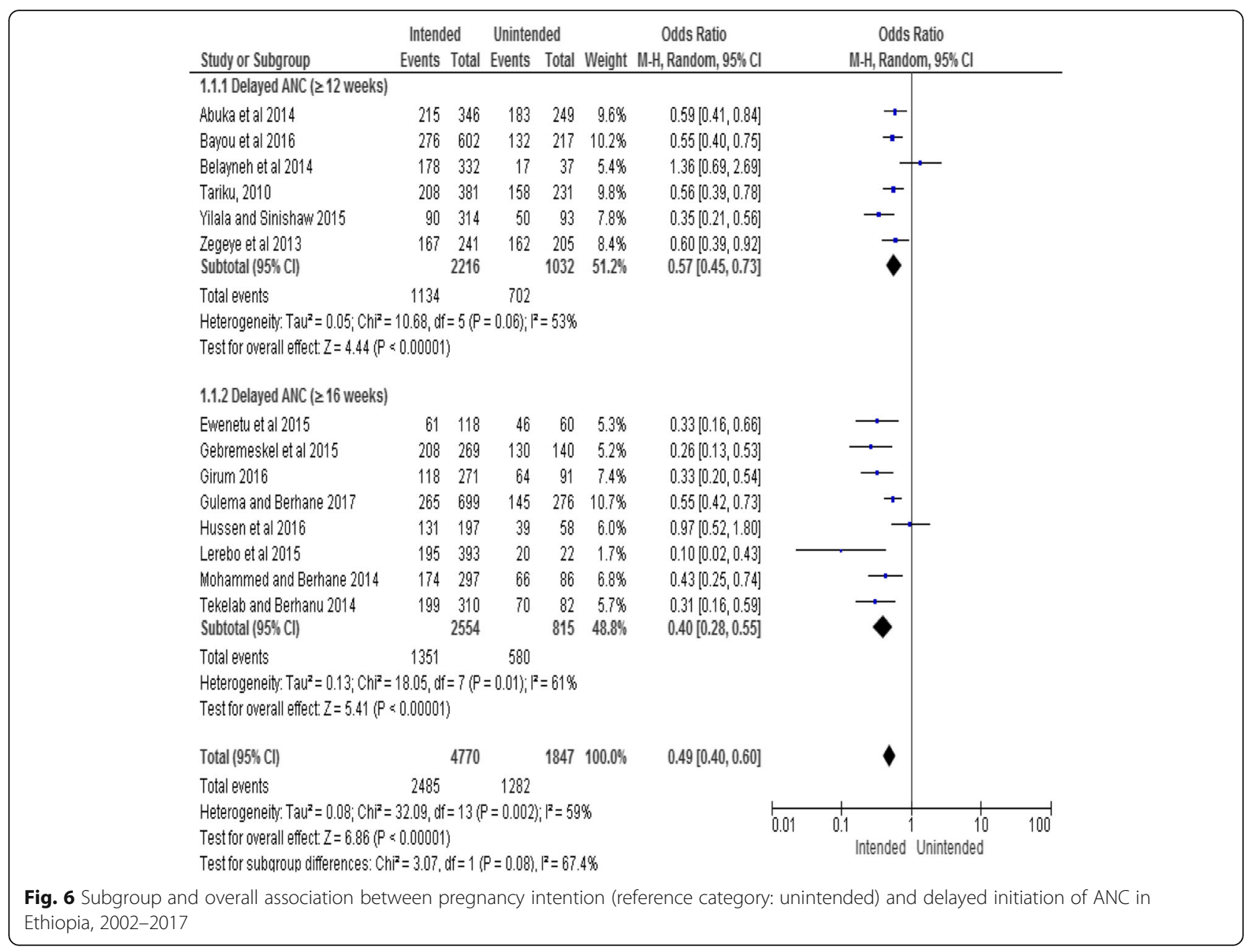

current efforts to improve maternal outcomes through adequate utilization of ANC in Ethiopia. The current systematic review supplied a summary of available evidence on the level of delayed initiation of ANC and associated factors in Ethiopia. The importance of systematic reviews to provide relevant information to transform health care delivery system and policy modification or ratification was well documented [56]. This systematic review summarized up-to-date empirical evidence and fleshed out key areas of action regarding delayed initiation of ANC in Ethiopia. This is an important step-forward to ensure maternal health program planners and policy makers in the country make informed decisions regarding where the corrective measures should be instituted and maximized.

Even though the WHO $[10,11]$ recommended initiation of ANC attendance not later than the first trimester of pregnancy, the reviewed evidence showed that the magnitude of delayed initiation of ANC is very high, at $64 \%$ in Ethiopia. This figure was almost in line with a comparative report of demographic and health survey data of twenty one sub-Saharan African countries [21] where, on average, more than two-thirds of the reproductive aged women initiated their first ANC after the first trimester of pregnancy. This might be due to several socio-cultural, economic and contextual factors including women's poor decision making power at a household level due to deeply rooted gender inequality, poor educational status, and poverty, which in turn could limit the women's ability to seek care earlier. The decision to early seek care and assistance during pregnancy among Ethiopian women especially in rural areas are linked with many cultural practices $[57,58]$, which were barrier to accessing services throughout a woman's pregnancy. Delayed initiation of ANC was a significant risk factor for maternal death, particularly among the disadvantaged women [22]. Hence countries need to prioritise efforts to improve the initiation of ANC.

According to this review, maternal age and education, husband's education, parity, knowledge of ANC and women's autonomy were influencing factors for delayed first ANC attendance in Ethiopia. The result of the current review was in agreement with the systematic review of studies $[43,44,59]$ conducted in other settings where maternal age, maternal education, husband's education, and 
Table 3 Summary of the test statistics of association between the remaining delay one, two and three factors with delayed initiation of ANC in Ethiopia, 2002-2017

\begin{tabular}{|c|c|c|c|c|c|}
\hline \multirow{2}{*}{$\begin{array}{l}\text { Predictor variable } \\
\text { Monthly income [ } \leq 1000 \text { ETB(50USD)] }\end{array}$} & \multicolumn{2}{|c|}{ Subgroup OR $(95 \% \mathrm{Cl})$} & \multirow{2}{*}{$\frac{1^{2}}{65 \%}$} & \multirow{2}{*}{$\frac{\text { Combined OR }(95 \% \mathrm{Cl})}{2.06(1.23,3.45)}$} & \multirow{2}{*}{$\frac{\text { Overall } 1^{2}}{91 \%}$} \\
\hline & I & $1.77(1.16,2.72)$ & & & \\
\hline & $\|$ & $2.26(0.96,5.29)$ & $94 \%$ & & \\
\hline \multirow[t]{2}{*}{ Marital status [In marriage] } & I & $0.92(0.55,1.54)$ & $77 \%$ & $0.81(0.56,1.16)$ & $68 \%$ \\
\hline & $\|$ & $0.68(0.38,1.22)$ & $57 \%$ & & \\
\hline \multirow[t]{2}{*}{ Maternal occupation [Employed] } & । & $0.76(0.53,1.09)$ & $83 \%$ & $0.75(0.61,0.93)$ & $74 \%$ \\
\hline & $\|$ & $0.74(0.57,0.97)$ & $66 \%$ & & \\
\hline Husband education [Attended primary/above] & $\|$ & $0.44(0.23,0.85)$ & $80 \%$ & & \\
\hline Women's autonomy [Autonomous] & । & $0.38(0.15,0.94)$ & $89 \%$ & & \\
\hline \multirow[t]{2}{*}{ Previous use of ANC [Previous use] } & । & $0.65(0.42,1.02)$ & $45 \%$ & $0.62(0.34,1.11)$ & $85 \%$ \\
\hline & $\|$ & $0.53(0.17,1.67)$ & $92 \%$ & & \\
\hline \multirow[t]{2}{*}{ Parity [Nulliparity] } & I & $0.51(0.42,0.61)$ & $0 \%$ & $0.46(0.36,0.58)$ & $67 \%$ \\
\hline & $\|$ & $0.42(0.27,0.66)$ & $81 \%$ & & \\
\hline \multirow[t]{2}{*}{ Partner involvement [Involved] } & I & $0.44(0.21,0.91)$ & $85 \%$ & $0.24(0.07,0.75)$ & $85 \%$ \\
\hline & $\|$ & $0.14(0.08,0.22)$ & $85 \%$ & & \\
\hline \multirow[t]{2}{*}{ Knowledge of ANC [Knowledgeable] } & I & $0.32(0.22,0.46)$ & $4 \%$ & $0.40(0.32,0.51)$ & $29 \%$ \\
\hline & $\|$ & $0.46(0.35,0.62)$ & $54 \%$ & & \\
\hline \multirow[t]{2}{*}{ History of abortion [Have history of abortion] } & I & $1.19(0.85,1.66)$ & $0 \%$ & $1.16(0.79,1.69)$ & $77 \%$ \\
\hline & $\|$ & $1.14(0.67,1.95)$ & $77 \%$ & & \\
\hline Pregnancy complication [Presence of complication] & $\|$ & $0.23(0.06,0.95)$ & $97 \%$ & & \\
\hline Means of identifying pregnancy [Urine] & । & $0.50(0.36,0.69)$ & $67 \%$ & & \\
\hline
\end{tabular}

Subgroup: I = Studies that defined delayed initiation of ANC (after 12 weeks of gestation), Subgroup: II = Studies that defined delayed initiation of ANC (after 16 weeks of gestation), $I^{2}$ is the percentage of total variance due to between study heterogeneity

parity were the influencing factors for delayed initiation of ANC. The possible reason for older women aged 31 to 49 delaying their first ANC might be that they most likely are uneducated, have poor knowledge of ANC, have experienced pregnancies without complications previously, are less fearful unlike younger women and may be more likely to be multiparous. Education of the mother and husband could play a great role in improving awareness of health matters in general, and the importance of ANC in particular. Having a better awareness may enable women to seek ANC and utilize the service early in pregnancy. This was particularly reflected in the systematic review of studies among non-western women in industrialized countries [45] where women's low level of educational status was associated with late entry into ANC.

Furthermore, a lack of knowledge about ANC is positively associated with delayed initiation of ANC. Women who had been provided with information regarding ANC, pregnancy risks and danger signs were more likely to initiate ANC early compared to women who did not have knowledge of these issues. This could motivate the women to initiate ANC early to better avoid the risks associated with pregnancy. It is anticipated that well informed women were more likely to make judicious choices about the proper utilization of ANC. It was also found that women's autonomy was a significant predictor of delayed initiation of ANC where non-autonomous women were more likely to postpone ANC, which could be due to the fact that they were under the influence of their partner or family (especially in male headed households), restricted to comply with family norms, had lack of family or social support, and a partner who was not available or who refused to accompany them. This was demonstrated in a systematic review of studies in the developing countries [44], where social support from family members, extent of ties within social networks, and obtaining health information from these sources highly influence timely utilization of ANC.

Additionally, the meta-analysis revealed that place of residence, maternal occupation, monthly income, and partner involvement were significantly associated with delayed ANC initiation. Rural women were more likely to delay their first ANC attendance than urban women. This could be explained by the fact that urban women would most likely have easy access to health care facilities, have a good awareness of health matters, and have better exposure to media. Moreover, unemployed women were more likely to delay initiation of ANC as compared to employed women. A similar finding was reported in other systematic reviews $[43,45]$ where not being in employment 
explained women's delayed entry into the care. It was also evidenced that women with high economic status were more likely to receive ANC earlier than those with a lower economic status [43, 44]. These financial constraints are in turn related to other barriers to seeking help, including transportation costs, the cost of obtaining care, or laboratory tests $[60,61]$.

Moreover, our finding suggests that women whose partner was involved in ANC were less likely to delay their first ANC attendance than women whose partner was not involved in ANC. Partner involvement in terms of initiating and/or supporting the idea to utilize ANC early, or by accompanying the pregnant mother to the health facility may have an important impact on the early attendance of ANC. In many traditions, the involvement of men in reproductive health has not been considered an important issue. In general male partners did not accompany their wives to attend ANC and other maternal health services [43]. The husband's lack of involvement in ANC may immensely affect the women's capability to initiate ANC early. It was found in a systematic review [62] that the involvement of men in ANC has a positive influence on the overall uptake of the service and its early attendance.

Furthermore, the meta-analysis identified factors such as pregnancy intention, presence of pregnancy complications and means of identifying pregnancy as an important factors that affect delayed initiation of ANC. This finding is consistent with a systematic review of small scale studies conducted in both developed and developing countries [63] on the relationship between pregnancy intention and timely initiation as well as obtaining adequate ANC. It was revealed that unintended pregnancy has a strong association with delayed initiation of first ANC services. Another systematic review [44] confirmed that women whose pregnancy was unintended tended to initiate ANC later than the first trimester of pregnancy. With regards to complications during pregnancy, the findings of this study is similar to a systematic review of literature [43] conducted in developing countries where pregnant women who did not experience obstetric complications were more likely to delay their first ANC compared to their counterparts.

In the current systematic review and meta-analysis, we observed some discrepancies in the included studies in defining the outcome variable "delayed initiation of ANC". Half of the included studies defined delayed initiation of ANC based on the cut-off point of 12 weeks of gestation, whereas the rest of the studies defined it based on 16 weeks. However the WHO $[10,11]$ defined late ANC initiation as entry into care after $12^{\text {th }}$ week of pregnancy. Conversely, in this review we noticed a contrasting type of definition across several studies [27-42] as well as ANC practice in health facilities [53], implying that there was poor compliance of the WHO recommendation on the timing of first ANC initiation in Ethiopia. Countries might prefer to adapt or contextualise the original clinical practice guidelines with some changes, depending on their setting, to effectively implement the recommendations. Even if recommendations from the parent clinical practice guidelines can be adapted, how they are implemented needs to address local issues. Thus countries may need to contextualise guideline by addressing those implementation issues so that care becomes more relevant to the local environments [64]. However, at least there should not be inconsistencies between the implemented specific health recommendation within the country's health care delivery system and the health research arena. Hence, we recommend to concerned parties in the health sector in Ethiopia, particularly the health research scholars, that there is a need to adhere to the WHO recommended guideline on the timing of ANC initiation. Moreover, any further adapted or contextualised guideline on the timing of ANC initiation needs to be followed or implemented consistently in a standardized way.

The current systematic review and meta-analysis was not without limitations. The first limitation was the exclusion of qualitative studies from the review, which might reveal other important factors affecting women's behaviour to delay ANC attendance or might otherwise corroborate the quantitative findings. Secondly, since our meta-analysis used Crude Odds Ratios, it might be difficult to fully ascertain the effect of the exposure factors on the outcome of interest. Thirdly, as all the included studies were crosssectional by design, it is difficult to establish temporal relationship between the outcome and exposure variables. Lastly, conducting meta-analysis despite the inherent heterogeneity between the included studies might have affected the quantitative findings. Our systematic review and meta-analysis also has some strengths. In this regard, we considered selection and inclusion of both published and unpublished literature which has the potential to minimize publication bias. Moreover, our search strategy was extensive using a number of major medical databases and other search engines. Lastly, we conducted a sub-group analysis of studies that employed different definitions of delayed initiation of ANC to appreciate the independent subgroup findings.

\section{Conclusion}

The current review revealed that nearly two thirds of women were delaying their first ANC visit in Ethiopia. The review pointed out various factors attributed to high level of delayed initiation of ANC in Ethiopia. Among these maternal age, place of residence, maternal education, husband's education, maternal occupation, family monthly income, pregnancy intention, parity, knowledge 
of ANC, women's autonomy, partner involvement, problem during pregnancy, and means of identifying pregnancy showed significant association with delayed initiation of ANC. Therefore, intervention efforts to improve ANC utilization in Ethiopia require targeting these impeding factors. Moreover, strategies should be designed to intensify advocacy of female education, women's empowerment activities need to be continued through economic reforms, family planning programs should be strengthened to reduce unintended pregnancies, and partner involvement in ANC should be promoted through different means of communication. Further qualitative studies are recommended to gain further insight into the societal and health system barriers that contribute to delayed initiation of ANC in Ethiopia.

\section{Additional files}

Additional file 1: PRISMA-P (Preferred Reporting Items for Systematic review and Meta-Analysis Protocols) 2015 checklist: recommended items to address in a systematic review protocol*. (DOC $85 \mathrm{~kb}$ )

Additional file 2: Search Strategy. (DOCX $28 \mathrm{~kb}$ )

\section{Abbreviations}

ANC: Antenatal care; Cl: Confidence interval; DHS: Demographic and Health Survey; ETB: Ethiopian birr; JBI: Joanna Briggs Institute; MAStARI: Meta-Analysis of Statistics Assessment and Review Instrument; M-H: Mantel-Haenszel; NSW: New South Wales; OR: Odds ratio; PRISMA: Preferred Reporting Items for Systematic Reviews and Meta-Analyses Protocols; USD: United States Dollar; WHO: World Health Organization

\section{Acknowledgments}

We are very grateful to the University of Newcastle, Australia for providing a full scholarship for the corresponding author, and free access to the digital online library to search the electronic databases that were considered for this review. We also would like to acknowledge Haramaya University for providing free internet access and an office.

Ethical approval and consent to participate

Not applicable.

\section{Funding}

Not applicable.

\section{Availability of data and materials}

The data that support the review findings of this study are available upon submitting a reasonable request to the corresponding author.

\section{Authors' contributions \\ GT, DL, CC, RS conceptualized the design of the systematic review. GT drafted the manuscript and is the guarantor of the review. All authors contributed to the development of the article search strategy, setting study selection criteria, the strategy for assessment of risk of bias, and data abstraction form. GT and AS involved in the screening, assessment of eligibility, selection of studies and critical appraisal as well as data extraction. $\mathrm{DL}, \mathrm{CC}, \mathrm{AS}$ and RS have participated in critically revising the manuscript for important intellectual contents. All authors read, provided feedback and approved the final manuscript.}

\section{Consent for publication}

Not applicable.

\section{Competing interests}

The authors declare that they have no competing interests.

\section{Publisher's Note}

Springer Nature remains neutral with regard to jurisdictional claims in published maps and institutional affiliations.

\section{Author details}

${ }^{1}$ Research Centre for Generational Health and Ageing, Faculty of Health and Medicine, University of Newcastle, Newcastle, Australia. ${ }^{2}$ School of Public Health, College of Health and Medical Sciences, Haramaya University, Harar, Ethiopia. ${ }^{3}$ Mothers and Babies Research Centre, Faculty of Health and Medicine, University of Newcastle, Newcastle, Australia.

Received: 18 July 2017 Accepted: 8 November 2017

Published online: 15 November 2017

\section{References}

1. Prata N, Passano P, Sreenivas A, Gerdts C. Maternal mortality in developing countries: challenges in scaling-up priority interventions. Women's Health. 2010;6(2):311-27.

2. WHO. Maternal mortality Fact sheet. 2016.

3. WHO. Trends in Maternal Mortality: 1990 to 2015 estimates by WHO, UNICEF, UNFPA, World Bank Group and the United Nations Population Division Excutive summary. 2015.

4. WHO. Trends in Maternal Mortality: 1990 to 2013. 2014.

5. Birmeta K, Dibaba Y, Woldeyohannes D. Determinants of maternal health care utilization in Holeta town, central Ethiopia. BMC Health Serv Res. 2013;13(256):10.

6. Ronsmans C, Graham W. Maternal mortality: who, when, where, and why. Lancet. 2006;368(9542):1189-200.

7. Tey N, Lai S. Correlates of and barriers to the utilization of health Services for Delivery in South Asia and sub-Saharan Africa. ScientificWorldJournal. 2013;2013

8. Godefay H, Byass P, Kinsman J, Mulugeta A. Understanding maternal mortality from top-down and bottom-up perspectives: case of Tigray region, Ethiopia. J Glob Health. 2015;5(1)

9. FMOH. HSTP Health Sector Transformation Plan. 2015.

10. Villar J, P B. WHO antenatal care randomized trial: Manual for the implementation for the new model. 2002.

11. WHO. WHO recommendations on antenatal care for a positive pregnancy experience. 2016.

12. CSA. Ethiopia Demographic and Health Survey 2011 Demographic surveillance Addis Ababa, Ethiopia and Calverton,Maryland. USA: CSA; 2011.

13. CSA. Ethiopian Demographci and Health Survey 2016.

14. CSA. Ethiopia Demographic and Health Survey. 2005.

15. Ayele D, Belayihun B, Teji K, Ayana D. Factors affecting utilization of maternal health Care Services in Kombolcha District, eastern Hararghe zone, Oromia regional state, eastern Ethiopia. Int Sch Res Notices. 2014;2014:7.

16. Abosse Z, Woldie M, Ololo S. Factors influencing antenatal care service utilization in Hadiya zone. Ethiop J Health Sci. 2010;20(2):75-82.

17. Dutamo Z, Assefa N, Egata G. Maternal health care use among married women in Hossaina, Ethiopia. BMC Health Serv Res. 2015;15(365):1-9.

18. CSA. Population Projection of Ethiopia for All Regions At Wereda Level from 2014-2017. 2014.

19. Melaku Y, Weldearegawi B, Tesfay F, Abera S, Abraham L, Aregay A, et al. Poor linkages in maternal health care services? Evidence on antenatal care and institutional delivery from a community-based longitudinal study in Tigray region, Ethiopia. BMC Pregnancy and Childbirth. 2014;14(418)

20. CSA. The Ethiopian mini health and demographic survey. Addis Ababa, Ethiopia, Calverton, Maryland, USA: Central statistical agency of Ethiopia; 2014.

21. Wang W, Alva S, Wang S, Fort A. Level and trends in the use of maternal health services in developing countries: DHS comparative reports 26: USAID. 2011

22. Cantwell R, Clutton-Brock T, Cooper G. Saving mothers' lives: reviewing maternal deaths to make motherhood safer: 2006-2008. The eighth report of the confidential enquiries into maternal deaths in the United Kingdom. BJOG. 2011;118(1):149-57.

23. Ziyo F, Matly F, Mehemd G, Dofany E. Relation between prenatal care and pregnancy outcome at Benghazi. Sudanese Journal of public health. 2012; 4(4):403-10.

24. Thaddeus S, Maine D. Too far to walk: maternal mortality in context. Soc Sci Med. 1994;38(8):1091-110.

25. Berhane Y, Gossaye Y, Emmelinb M, Hogberg U. Women's health in a rural setting in societal transition in Ethiopia. Soc Sci Med. 2001;2001(53):1525-39. 
26. Mekonnen Y, Mekonnen A. Utilization of maternal health Care Services in Ethiopia. Calverton: Maryland, USA; 2002.

27. Abosse Z, Woldie M, Ololo S. Factors influencing antenatal care service utilization in hadiya zone. Ethiop J Health Sci. 2010;20(2):75-82.

28. Damme T, Workineh D, Gmariam A. Time of Antenatal Care Booking and Associated Factors Among Pregnant Women Attending Ambo Town Health Facilities, Central Ethiopia. 2015

29. Ewnetu W, Assegid S, Wondafrash W, Ewnetu H. Factors associated with late antenatal care initiation in an Ethiopian clinic. Research. 2015.

30. Gudayu T, Woldeyohannes S, Abdo A. Timing and factors associated with first antenatal care booking among pregnant mothers in Gondar town; north West Ethiopia. BMC Pregnancy Childbirth. 2014;14(1):287.

31. Lerebo W, Kidanu A, Tsadik M. Magnitude and associated factors of late booking for antenatal Care in Public Health Centers of Adigrat town, Tigray. Ethiopia Clinics Mother Child Health. 2015:12(171):2.

32. Tekelab T, Berhanu B. Factors associated with late initiation of antenatal care among pregnant women attending antenatal Clinic at Public Health Centers in Kembata Tembaro zone, southern Ethiopia. Science, Technology and Arts Research Journal. 2014;3(1):108-15.

33. Yilala Y. Assesment of late initiation of antenatal care and associated factors among antenatal care attendees in selected health centers of Addis Ababa, Ethiopia (Master Thesis): AAU; 2015.

34. Belayneh T, Adefris M, Andargie G. Previous Early Antenatal Service Utilization Improves Timely Booking: Cross-Sectional Study at University of Gondar Hospital, Northwest Ethiopia. 2014.

35. Abuka T, Alemu A, Birhanu B. Assessment Of Timing Of First Antenatal Care Booking And Associated Factors Among Pregnant Women Who Attend Antenatal Care At Health Facilities In Dilla Town, Gedeo Zone, Southern Nations, Nationalities, And Peoples Region, Ethiopia, 2014: AAU; 2014.

36. Bayou Y, Mashalla Y, Tshweneagae G. The adequacy of antenatal care services among slum residents in Addis Ababa, Ethiopia. BMC Pregnancy Childbirth. 2016;16(1):142

37. Gudayu T. Proportion and factors associated with late antenatal care booking among pregnant mothers in Gondar town, north West Ethiopia. Afr J Reprod Health. 2015;19(2):93-9.

38. Girum T. Assessment of timing of first antenatal care visit and associated factors among pregnant women attending antenatal Care in Dilla Town Governmental Health Institutions, southern Ethiopia. Alternative \& Integrative Medicine. 2016;5(3)

39. Amentie M, Abera M, Abdulahi M. Utilization of antenatal care services and influencing factors among women of child bearing age in Assosa District, Benishangul Gumuz regional state, West Ethiopia. Global Journal of Medical Research. 2015;15(2)

40. Gebremeskel F, Dibaba Y, Admassu B. Timing of first antenatal care attendance and associated factors among pregnant women in Arba Minch town and Arba Minch District, Gamo Gofa Zone, South Ethiopia. 2015.

41. Haileselassie D. Magnitude and factors affecting late initiation of antenatal care service utilization among pregnant women in government health institutions, Mekelle Town, Ethiopia (Master Thesis): AAU: 2010.

42. Hussen S, Melese E, Dembelu M. Timely Initiation of First Antenatal Care Visit of Pregnant Women Attending Antenatal Care Service. 2016.

43. Simkhada B, Teijlingen E, Porter M, Simkhada P. Factors affecting the utilization of antenatal care in developing countries: systematic review of the literature. J Adv Nurs. 2007;61(3):244-60.

44. Hajizadeh S, Tehrani F, Simbar M, Farzadfar F. Factors influencing the use of prenatal care: a systematic review. J midwifery. Reprod Health. 2016;4(1):544-57.

45. Boerleider A, Wiegers T, Manniën J, Francke A, Devillé W. Factors affecting the use of prenatal care by non-western women in industrialized western countries: a systematic review. BMC Pregnancy Childbirth. 2013;13(81)

46. Moher D, Shamseer $L$, Clarke M, Ghersi D, Liberati A, Petticrew M, et al. Preferred reporting items for systematic review and meta-analysis protocols (PRISMA-P) 2015 statement. Systematic Reviews. 2015;4(1)

47. Moher D, Liberati A, Tetzlaff J, Altman D. Preferred reporting items for systematic reviews and meta-analyses: the PRISMA statement. PLoS Med. 2009;6(7)

48. Reuters T, inventorEndNote X 7.3.1 (Bld 8614), Cite While You Write TM Patented technology U.S patent number 8,092,24119888-2015.

49. Institute TJB. Joanna Briggs institute Reviewers' manual 2014 edition. Adelaide: Adelaide University; 2014

50. Cochrane C, inventorReview Manager (RevMan) [Computer program]. Version 5.3. Copenhagen: The Nordic Cochrane Centre, The Cochrane Collaboration 2014.
51. Higgins J, Hompson S. Quantifying heterogeneity in a meta-analysis. 2002

52. StatsDirect Ltd. StatsDirect statistical software. England: StatsDirect Ltd.; 2013. http://www.statsdirect.com.

53. $\mathrm{FMOH}$. Antenatal Care Module: 13. In: Providing focused antenatal care; 2010.

54. Beller E, Glasziou P, Altman D, Hopewell S, Bastian H, Chalmers I, et al. PRISMA for abstracts: reporting systematic reviews in journal and conference abstracts. PLoS Med. 2013;10(4)

55. Vintzileos A, Ananth C, Smulian J, Scorza W, Knuppel R. The impact of prenatal care on neonatal deaths in the presence and absence of antenatal high-risk conditions. Am J Obstet Gynecol. 2002;186(5):1011-6.

56. Moat K, Lavis J, Wilson M, Røttingen J, Barnighausen T. Twelve myths about systematic reviews for health system policymaking rebutted. J Health Serv Res Policy. 2013;18(1):44-50.

57. USAID/MCHIP. Cultural Barriers to Seeking Maternal Health Care in Ethiopia: A Review of the Literature. 2012.

58. Warren C. Care seeking for maternal health: challenges remain for poor women. Ethiopian Journal of Health Development. 2010;24(Special 1):100-4.

59. Jong E, Jansen D, Baarveld F, Schans C, Schellevis F, Reijneveld S. Determinants of late and/or inadequate use of prenatal healthcare in highincome countries: a systematic review. Eur J Pub Health. 2011;22(6):904-13.

60. Yang Y, Yoshitoku Y, Harun R, Junichi S. Factors Affecting the utilization of antenatal care services among women in Kham district, Xiengkhouang province, Lao PDR. Nagoya J Med Sci. 2010;72:23-33.

61. Anyait A, Mukanga D, Oundo G, Nuwaha F. Predictors for health facility delivery in Busia district of Uganda: a cross sectional study. BMC Pregnancy Childbirth. 2012;12(132)

62. Ayebare E, Mwebaza E, Mwizerwa J, Namutebi E, Kinengyere A, Smyth R. Interventions for male involvement in pregnancy and labour: a systematic review. 2006.

63. Dibaba $Y$, Fantahun $M$, Hindin $M$. The effects of pregnancy intention on the use of antenatal care services: systematic review and meta-analysis. Reprod Health. 2014;10(50)

64. Dizon J, Machingaidze S, Grimmer K. To adopt, to adapt, or to contextualise? The big question in clinical practice guideline development. BMC Res Notes. 2016;9(442)

65. Zegeye A, Bitew B, Koye D. Prevalence and determinants of early antenatal care visit among pregnant women attending antenatal Care in Debre Berhan Health Institutions, Central Ethiopia. Afr J Reprod Health. 2013;17(4):130-6.

66. Fisseha G, Miruts G, Tekie M, W/Michael A, Yemane D, Gerezigiher T. Predictors of timing of first antenatal care booking at public health centers in Mekelle City, northern Ethiopia. J Gynecol Obst. 2015;3(3):55-60.

67. Gulema H, Berhane Y. Timing of first antenatal care visit and its associated factors among pregnant women attending public health facilities in Addis Ababa, Ethiopia. Ethiopian Journal of Health Sciences. 2017;27(2):139-46.

68. Mohammed Z, Berhane E. Assessment of timing of first antenatal care (ANC) initiation and associated factors among pregnant women in selected public health centres in Addis Ababa, Ethiopia, 2014: AAU; 2014

\section{Submit your next manuscript to BioMed Central and we will help you at every step:}

- We accept pre-submission inquiries

- Our selector tool helps you to find the most relevant journal

- We provide round the clock customer support

- Convenient online submission

- Thorough peer review

- Inclusion in PubMed and all major indexing services

- Maximum visibility for your research

Submit your manuscript at www.biomedcentral.com/submit 